\title{
Ergonomic analysis of work activity for the purpose of developing training programs: the contribution of ergonomics to vocational didactics
}

\author{
Sylvie Ouellet ${ }^{1}$ \\ Institut de recherche Robert-Sauvé en santé et en sécurité du travail, 505 De Maisonneuve Blvd. West, Montréal, \\ Québec, H3A 3C2, Phone: 514-288-1551,Fax: 514-288-6097,ouellet.sylvie@irsst.qc.ca
}

\begin{abstract}
Questions related to job skills and the teaching situations that best promote skill development are investigated by specialists in various fields, notably among them, ergonomists. This paper presents the findings of an ergonomic intervention study whose aim was to develop a meat-deboning training program by taking into account both the training content to be constructed and the working conditions that might facilitate or hinder skill development. One-on-one interviews and group discussions, on-the-job and videotape playback observations, as well as self-confrontation interviews were carried out. Activity analysis revealed major variability in work methods. The reasoning behind the experienced workers' actions and the experiential job knowledge they had developed were brought to light and served to develop the training content. The determining factors in the choice of work methods were identified, allowing adjustments to be made to the working conditions that might hinder skill development. The ergonomic process that implied taking working conditions into account in our study may make a significant contribution to vocational didactics, which is based on the cognitive analysis of work for the purpose of improving the effectiveness of job-skills training.
\end{abstract}

Keywords: ergonomic analysis, vocational didactics, work activity, job-skills training, training program

\section{Introduction}

Questions related to job skills and the teaching situations that are most conducive to skill development are investigated by specialists in various fields, notably among them, ergonomists. Ergonomic studies, which are conducted in various industry sectors and concern various occupations, show the contribution made by ergonomic analysis of work activity to the production of knowledge on real work and the contexts in which it is performed. This knowledge can in turn contribute to the development of training programs $[1,3,4,5,7,12]$. First, work activity analysis reveals the conceptual structure of the job task, as demonstrated by vocational didactics specialists
$[6,14]$. Second, by nature, ergonomic analysis "implies a process that takes into consideration the conditions under which the work is performed" (free translation) [9]. This process concerns the margins of manoeuvre available to workers for introducing compromises that enable them both to attain production objectives and protect their health [8]. Using this approach, an ergonomic intervention study was conducted in the agrifood industry. The study had a twofold objective: that of developing new knowledge about job-skills training, and that of responding to a company's request for the development of training content on meat deboning and guidelines on how to structure this training.

\footnotetext{
${ }^{1}$ Corresponding author. E-mail : ouellet.sylvie@irsst.qc.ca
} 
This paper reports on the contribution made by an ergonomic process focused on activity analysis to the identification of knowledge elements that permit skill building and of factors that determine work methods, ultimately for the purpose of making adjustments to work and learning situations.

\section{Methodology}

The study was conducted in a meat-processing plant operating in the agrifood sector. A preliminary step involved selecting six experienced meat boners recognized by their peers for their know-how and conducting one-on-one interviews with them. The purpose of the interviews was to (1) learn about the workers' experience; (2) understand the nature of the work performed; and (3) learn about the difficulties faced and discomforts experienced. The average age of the six experienced workers, all of whom were right-handed, was $44 \pm 7.9$ years (34 to 54 years), and they had an average of $11 \pm 7.7$ years ( 5 to 25 years) of experience with the company.

We then carried out four steps. First, we observed the workers at their workstations over a two-day period to familiarize ourselves with the organization of the work, the steps involved in the job task and the various factors possibly determining the choice of work methods. Second, we described and analyzed in detail the work methods and movements made during each step of the task by selecting 10 consecutive incident-free work cycles from videotaped recordings, which gave us five cycles involving right-side meat cuts and five cycles involving left-side meat cuts. Our analysis took into account the temporal breakdown of the steps in the task, the order in which the steps were followed, the manner in which the piece of meat was positioned and handled, the types of knife grips used in each step, and the characteristics of the knife strokes (direction, angle, and length), as well as the repetitiveness and range of joint motion involved. Third, on the basis of one-on-one selfconfrontation interviews lasting 2.5 hours with each worker, we analyzed the strategies used in order to validate the observation results obtained and to identify the determining factors in the choice of work methods. These interviews also enabled us to document the cognitive component of the movements made [2] by encouraging the operators to verbalize the sensorimotor information they processed in making their choices and the reasoning behind their choices. The fourth step consisted of a two-day group meeting, for a total of 14.5 hours. One of the discussions at this meeting concerned the work methods and cues used to perform the job task. The meeting was supplemented by practice periods in the production room that enabled us to verify the knowledge elements incorporated into certain work methods and to systematically identify their advantages and disadvantages in terms of both production quality and musculoskeletal disorder (MSD) prevention. The aim of the last step was to obtain consensus within the group of workers on the content elements to be included in the meat-deboning training program.

\section{Results}

The deboning task consists of removing bones from a leg of pork using a knife. The task is carried out in sequences on a moving conveyor belt operating at a steady pace that corresponds to the arrival of a piece of meat every 18 seconds. Between each work cycle, the meat boner has to sharpen his knife. The focus of our study was the task of removing the femur. Three meat boners carry out the "femur" sequence, handling one piece of meat in three and having 54 seconds to complete the sequence.

\subsection{Identification of the determining factors for the purpose of understanding the reasoning behind the actions}

Our analysis of the work methods revealed major variability in intra- and interindividual worker practices. This variability was apparent in several aspects of the meat deboning task, specifically (1) the cycle duration; (2) the order in which the steps were followed; (3) the number and length of the knife strokes; (4) the positioning and moving of the piece of meat; (5) the types of knives used; (6) the knife grips used; and (7) the manner in which each step was carried out.

In order to understand the reasoning behind the meat boners' choices of work methods and to highlight the knowledge elements underlying this reasoning, we questioned them about the factors that determined their practices. Figure 1 shows the different factors that determine their work methods. For example, some workers explained that when a piece of meat approaches their workstation, they immediately identify whether if it is a right-side or left-side meat cut because the work method differs accordingly. The workers estimate the amount of time required to remove the bone according to whether it is a right- or left-side cut, the quality of the work performed up- 
the quality of the work performed upstream (length of the shank, quality of the trimming, position of the piece on the conveyor belt), and the need or not to sharpen their knife before the cycle starts.

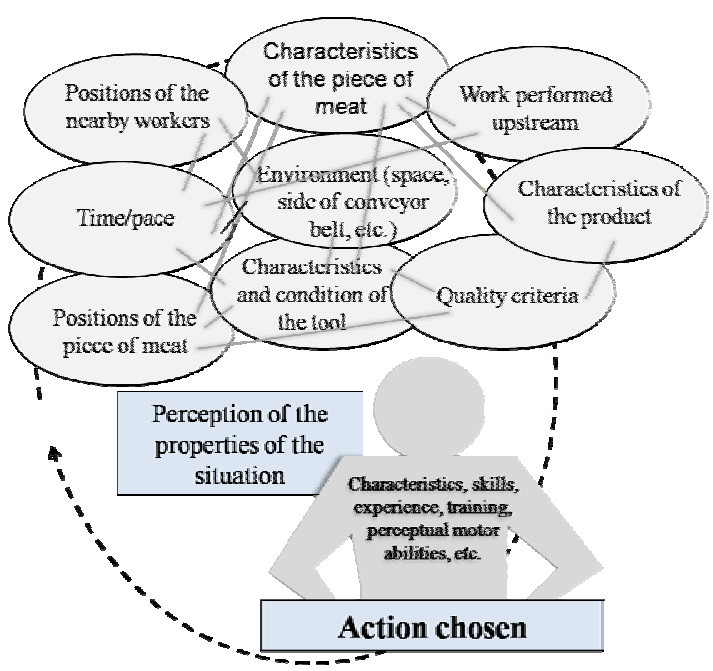

Figure 1: Factors determining the meat boners' work methods

If the meat boner considers that he needs a little more time because of certain determining factors, he will try to start his cycle on the conveyor belt sooner. However, to do so, he must first take the position of his upstream co-worker into account in order to avoid injuring him with his knife. If the upstream worker is behind in his own cycle, the meat boner will not be able to start his cycle sooner, which in turn obliges him to speed up (fast movements) or to encroach on the downstream workspace at the end of his cycle. The workers therefore take a number of factors into account to perform their work efficiently.

\subsection{Identification of the determining factors for the purpose of making adjustments to the work and learning situations}

The process of designing training programs also raises the question of the conditions under which the trainees will be working. The discussions that took place during the one-on-one interviews and the group meeting led to the identification of certain determining factors that required adjustment in order to improve the work situation of the regular meat boners and the trainees. For example, the determining factors in the number of knife strokes made in the piece of meat are as follows: (1) the cutting quality of the knife (good or not); (2) the quality of the finished product (good or not), and the fact that the number of knife strokes is one of a set of knowledge elements incorporated into the work method learned and/or chosen. In this regard, the workers mentioned that it was important to limit the number of knife strokes in order to reduce the workload and lost time and to ensure a good quality product.

In order to adjust some of these determining factors, it was necessary to backtrack along the chain of determining factors to identify the "determinants of these determining factors." Figure 2 shows the determinants of the quality of the knife cut (point 1) that were identified in discussions with the meat boners.

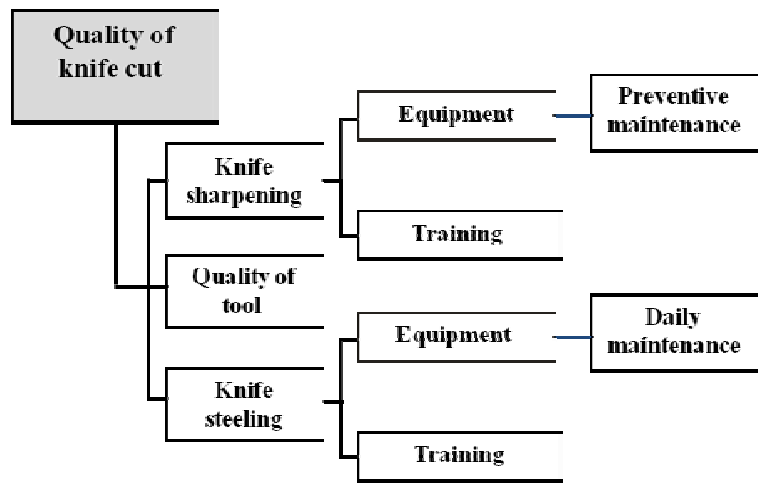

Figure 2: Determinants of the quality of the knife cut

Recommendations regarding some of these determinants were submitted to the company. For example, the deboning instructors had never received any training on knife sharpening, an operation that consists of realigning the knife's cutting edge to the centre using a machine equipped with a sandpaper belt. The observations made also revealed the malfunction of the machine. Recommendations regarding knifesharpening training and machine maintenance were then made to both the instructors and the person responsible for equipment maintenance, and regarding the purchase of a few useful accessories that would improve sharpening techniques, such as a less abrasive belt for the finishing stage of sharpening.

\subsection{Knowledge elements workers need to choose and build work methods}

Learning to perform a manual task is not a matter of simply imitating movements. To promote skill development, that is, the ability to mobilize a set of knowledge elements at the appropriate time, it appeared important to us to identify the knowledge elements that would help the trainees make appropriate 
choices. During the self-confrontation interviews, the workers were asked to express in words the advantages and disadvantages of the different methods observed. The information collected was then integrated into the training manual. For example, Table 1 shows that the fact of using one knife stroke to remove meat from the side of the bone makes it possible to reduce the number of knife strokes, but has the disadvantage of leaving more meat on the bone if the technique is not thoroughly mastered. This information was integrated into a training manual used as a reference tool by the worker-instructors.

Table 1: Advantages and disadvantages of two techniques used by the workers to remove meat from the side of the joint [11]

\begin{tabular}{|l|l|}
\hline \multicolumn{1}{|c|}{$\begin{array}{c}\text { No. of Knife } \\
\text { Strokes }\end{array}$} & \multicolumn{1}{c|}{ Advantages/Disadvantages } \\
\hline \multirow{3}{*}{ stroke } & $\begin{array}{l}\text { Advantage: } \\
\text { Requires one less knife stroke } \\
\text { Disadvantages: } \\
\text { May leave meat on the joint } \\
\text { Harder to master }\end{array}$ \\
\hline \multirow{3}{*}{ strokes } & $\begin{array}{l}\text { Advantages: } \\
\text { Leaves less meat on the joint } \\
\end{array}$ \\
& $\begin{array}{l}\text { Easier to master } \\
\text { Makes it easier to see where to cut } \\
\text { Disadvantage: } \\
\text { Requires one additional knife stroke }\end{array}$ \\
\hline
\end{tabular}

\section{Discussion}

The ergonomic analysis of the work activity carried out in this study made a major contribution at several levels by (1) providing an understanding of the reasoning behind the actions of the experienced meat boners; (2) identifying the determining factors in their practices, for the purpose of making adjustments to the working conditions, which were often the same as the learning conditions; and (3) allowing the workers to verbalize the job skills and knowledge mobilized during the activity, for the purpose of making them more accessible to trainees. The individual interviews and the group meeting provided an opportunity to validate this information, to discuss the different knowledge elements integrated into the work methods, and to verbalize the various "tricks of the trade" used to facilitate the work. One of the most important contributions of the meetings held during the study was that they promoted worker participation in the development of the training content, making it more representative of the real work performed in the eyes of all the company workers, and therefore, more credible in the trainees' eyes. Moreover, the dynamic created throughout this content development process fostered awareness, among the stakeholders and worker-instructors, of the complexity of the task to be learned and of the importance of creating conditions conducive to development of the skills required for efficient deboning.

\subsection{Ergonomic analysis of the work: contribution to vocational didactics}

The fact of relating work activity analysis to jobskills training is not new. It originates in studies conducted in the field of work psychology [10]. These studies lent support to the more recent discipline of vocational didactics by providing methods for implementing a work analysis process focused on "training and job-skills development" (free translation) [13]. In vocational didactics, work activity analysis has a dual purpose: it serves to build training content corresponding to the job task in question and uses real work situations as supports for job-skills training. Vocational didactics is based on the cognitive analysis of work for the purpose of improving the effectiveness of job-skills training [15].

Furthermore, it appears important to us that not only must the cognitive aspect of the work be taken into consideration, but also the conditions under which it is carried out. First, these conditions may pose a risk of injury to workers and trainees, and second, they may hinder skill development. In this regard, we concur with the idea put forward by Pastré et al. [13] to the effect that certain situations may offer development potential while others may not, or worse still, may even limit and inhibit the conceptualization processes. Therefore, action must also be taken to adjust work situations in such a way as to enable individuals to develop their ability to act appropriately, and ergonomics may make an important contribution to the attainment of this objective. There is therefore good reason for collaborative efforts to be made between ergonomists and vocational didactics specialists.

\section{Conclusion}

Work activity is a key consideration in job-skills training. To design training programs, we must take into account not only the know-how that individuals use in carrying out their work activity, but also the conditions under which the activity must be carried out. This will allow for the development of appropri- 
ate training content and for adjustments to be made to conditions that could hinder trainees' ability to acquire skills and protect their health. The ergonomic process used in this study, particularly the detailed analysis of movements, made the following possible: (1) discussions that elucidated the reasoning behind the experienced meat boners' actions; (2) identification of the knowledge elements underlying this reasoning; and (3) identification of the determining factors in the choice of work methods that required adjustment in order to improve the working and learning situations. Interesting opportunities exist for collaborative efforts between ergonomists and vocational didactics specialists to improve job-skills training.

\section{References}

[1] M. Authier, Analyse ergonomique des stratégies de manutentionnaires experts et novices, Ph.D. Thesis, Université de Montréal, 1996.

[2] F. Bourgeois and F. Hubault, Prévenir les TMS. De la biomécanique à la revalorisation du travail, l'analyse du geste dans toutes ses dimensions, ACTIVITÉS 2 (1) (2005), 17 p.

[3] K. Chassaing, Élaboration, structuration et réalisation des gestuelles de travail : les gestes dans l'assemblage automobile et dans le coffrage des ponts d'autoroute, Ph.D. Thesis, specialization: ergonomics. Conservatoire national des arts et métiers, Paris, 2006.

[4] C. Chatigny, La construction de ressources opératoires. Construction à la conception des conditions de formation en situation de travail, Ph.D. Thesis. Conservatoire national des arts et métiers, Paris, 2001.
[5] D. Denis, M. St-Vincent, M.. Gonella, F. Couturier, R. Trudeau, Analyse des stratégies de manutention chez des éboueurs au Québec, Pistes de réflexions pour une formation, Studies and Research Projects, IRSST, Montréal, 2007.

[6] M. Didier, Principes de didactique professionnelle, Séminaire BTS Assistant de Manager. Paris, at the Cité internationale universitaire de Paris, 2007.

[7] C. Gaudart, Transformations de l'activité avec l'âge dans des tâches de montage automobile sur chaîne, Ph.D. Thesis in ergonomics. École Pratique des Hautes Études, Paris, 1996.

[8] F. Guérin, A. Laville, F. Daniellou, J. Duraffourg, A. Kerguelen, Comprendre le travail pour le transformer. La pratique de l'ergonomie, 3rd edition. ANACT, 2006, 287 p.

[9] M. Lacomblez, Analyse du travail et élaboration des programmes de formation professionnelle, Relations industrielles, 58 (3), 2001, 543-578.

[10] J. Leplat, Psychologie de la formation. Jalons et perspectives, Choix de texte (1955-2002), Editions OCTARES, Toulouse, 2002, 293 p.

[11] S. Ouellet, Acquisition d'habiletés motrices à la découpe de viande et prévention des troubles musculo-squelettiques : apport de l'analyse ergonomique à la conception de formation, Ph.D. Thesis, Université du Québec à Montréal, Montréal, 2009.

[12] S. Ouellet, N. Vézina, J. Chartrand, P.-P. Perrier, J.-L. Malo, L'implantation de la rotation de postes : un exemple de démarche préalable, PISTES 5 (2) (2003), 24 p.

[13] P. Pastré, P. Mayen, G. Vergnaud, La didactique professionnelle, Revue française de pédagogie 154 (2006), 145-198.

[14] P. Pastré, L'analyse du travail en didactique professionnelle, Revue française de pédagogie 138, 2002, 9-17.

[15] P. Pastré, Didactique professionnelle et développement, Psychologie Française 42 (1) (1997), 89-100. 